\title{
The lectin-like domain of thrombomodulin protects against ischaemia-reperfusion lung injury
}

\author{
N. Geudens*, M. Van de Wouwer", , B.M. Vanaudenaerde ${ }^{+}$, R. Vos $^{+}$, \\ C. Van De Wauwer*, G.M. Verleden ${ }^{+}$, E. Verbeken ${ }^{\S}$, T. Lerut ${ }^{f}$, \\ D.E.M. Van Raemdonck*,f and E.M. Conway ${ }^{\#, \oplus}$
}

ABSTRACT: Ischaemia-reperfusion injury of the lung is a major cause of morbidity and mortality, particularly following lung transplantation, the mainstay treatment for patients with end-stage pulmonary disease. Effective measures to prevent this complication are lacking. Thrombomodulin (TM) is an endothelial cell receptor and cofactor for thrombin-mediated generation of the anticoagulant and anti-inflammatory activated protein C (APC). The N-terminal lectin-like domain (LLD) of TM has no direct effects on coagulation, but has distinct anti-inflammatory properties, interfering with leukocyte adhesion, complement activation and cytokine generation, all of which are hallmarks of ischaemia-reperfusion injury.

Using a murine model of lung ischaemia-reperfusion injury (90 min ischaemia, $4 \mathrm{~h}$ reperfusion), the present study shows that mice lacking the LLD of TM respond with increased extravasation of neutrophils and macrophages into the lung parenchyma and bronchoalveolar fluid (BALF), with

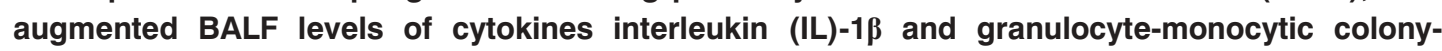
stimulating factor (GM-CSF). Pre-treatment of wild-type mice with recombinant LLD, as compared with controls, significantly suppresses protein leakage and accumulation of leukocytes in the BALF.

These novel findings support further evaluation of recombinant lectin-like domain of thrombomodulin to protect the lung against tissue-damaging pro-inflammatory responses following ischaemia-reperfusion.

KEYWORDS: Coagulation, inflammation, mouse, protein C system, transplant

L

ung transplantation has become the standard treatment for patients with most end-stage parenchymal and vascular pulmonary diseases. In spite of major surgical advances, better organ preservation techniques, and the development of safer and more effective immunosuppressive approaches, lung transplantation continues to be complicated by ischaemiareperfusion injury, which significantly impacts on short- and long-term outcomes [1, 2].

The cellular and molecular mechanisms underlying ischaemia-reperfusion injury are complex and remain incompletely understood. Nonetheless, major insights have recently been gained, and there are several well-defined features. These include: an influx of activated inflammatory cells; the release of pro-inflammatory cytokines [3-5]; local and systemic accumulation of chemokines and reactive oxygen species [6]; activation of complement [7]; increases in thromboxanes; cellular apoptosis; and reductions in nitric oxide (reviewed in [1]). Thus, therapeutic strategies have been devised to limit the severity of ischaemia-reperfusion injury with, for example: 1) complement inhibition; 2) neutralisation of interleukin (IL)-8 [8]; 3) use of antioxidants [8, 9]; 4) use of vasodilators, such as nitric oxide; 5) inhibition of macrophage activation [10]; 6) interference with leukocyte adhesion [11, 12]; 7) blocking generation of inflammatory arachidonic acid metabolites [13]; 8) suppression of the nuclear factor (NF)- $\mathrm{B}$ pro-inflammatory signalling pathway [14]; and 9) promoting cell survival $[15,16]$. Although these innovative therapeutic manoeuvres are showing promise in animal models, few have entered the clinic. Thus, ischaemia-reperfusion injury remains a highly relevant but largely unsolved problem, and novel therapeutic and/or preventative measures are urgently needed.

Thrombomodulin (TM) is a pan-endothelial cell, transmembrane glycoprotein receptor that, via its
AFFILIATIONS

*Laboratory of Experimental Thoracic Surgery,

"Center for Transgene Technology and Gene Therapy,

+Laboratory of Pneumology,

${ }^{\S}$ Dept of Morphology and Molecular

Pathology, University of Leuven,

\#VIB Vesalius Research Center, and ${ }^{f}$ Dept of Thoracic Surgery, University Hospital Gasthuisberg, Leuven, Belgium.

CORRESPONDENCE

E.M. Conway

VIB Vesalius Research Center

University of Leuven (KU Leuven)

Herestraat 49

B-3000 Leuven

Belgium

Fax: 3216345990

E-mail: ed.conway@

med.kuleuven.be

Received:

November 222007

Accepted after revision:

May 092008

SUPPORT STATEMENT

This work is supported by grants from the KU Leuven (OT/03/55) and the

Flanders Fund for Scientific Research (G.0282.07, G3C04.99), where

D.E.M. Van Raemdonck is a senior research fellow. E.M. Conway was supported by National Institutes of Health (Bethesda, MD, USA) Grant R01-HL067846

STATEMENT OF INTEREST

None declared.

European Respiratory Journal

Print ISSN 0903-1936

Online ISSN 1399-3003 
structural domains, provides vasculoprotection through several distinct molecular pathways (reviewed in [17]). Structurally, TM is comprised of five domains: a C-terminal cytoplasmic tail, a single membrane-spanning domain, an extracellular juxtamembranous serine-threonine rich region, six epidermal growth factor (EGF)-like repeats, and finally an $\mathrm{N}$-terminal C-type lectin-like domain (LLD) joined to the first EGF-like repeat via a short hydrophobic module. EGF-like repeats three to six provide critical cofactor activity for thrombin-mediated activation of the physiologically relevant anticoagulant and anti-inflammatory protein C (PC). Recent studies have revealed that the LLD of TM has distinct antiinflammatory properties, interfering with neutrophil and monocyte adhesion, suppressing activation of mitogen-activated protein (MAP) kinase and NF- $\kappa$ B pathways, promoting cell survival, interfering with complement activation [18, 19], and blocking the activity of the pro-inflammatory cytokine, high mobility group box 1 (HMGB1) [20]. Mice that lack the LLD of TM (TM ${ }^{\mathrm{LeD} / \mathrm{LeD}}$ mice) are more sensitive to pro-inflammatory stimuli and myocardial ischaemia-reperfusion injury, whereas administration of recombinant LLD of TM protects against endotoxin-induced sepsis and inflammation $[19,20]$.

In view of the diverse and potent anti-inflammatory properties of the LLD of TM, loss-of-function and gain-of-function approaches in mouse models [21] were used to examine the role of this structure in protecting against ischaemia-reperfusion injury of the lung.

\section{MATERIALS AND METHODS \\ Mice}

Female Swiss outbred mice were obtained from Janvier (Savigny/Orges, France). Mice lacking the N-terminal LLD of $\mathrm{TM}$ ( $\mathrm{TM} \mathrm{LeD}^{\mathrm{LeD}}$ mice) were previously generated [18]. $\mathrm{TM}^{\mathrm{LeD} / \mathrm{LeD}}$ mice and their wild-type counterparts $\left(\mathrm{TM}^{\mathrm{wt} / \mathrm{wt}}\right.$ mice), were obtained from intercrosses of $\mathrm{TM}^{\mathrm{LeD} / \mathrm{wt}}$ mice. Both lines were maintained in the same genetic background at the same generation, thereby allowing direct comparisons. $\mathrm{TM}^{\mathrm{LeD} / \mathrm{LeD}}$ mice express normal antigenic levels of $\mathrm{TM}$, and activation of PC is intact and unaffected by deletion of the LLD [18]. Experiments were performed on mice aged 8-10 weeks. Animals were housed in cages under specific pathogen-free conditions and fed ad libitum with a standard diet. Studies were approved by the University of Leuven Animal Ethics Committee (Leuven, Belgium).

\section{Hydrodynamic gene delivery}

In vivo gene delivery of the LLD in mice has been previously reported [19]. The cDNA encoding the first 155 amino acids of the LLD of murine TM was subcloned into pSecTag2HygroACMV (Invitrogen, Merelbeke, Belgium; referred to as pSec), resulting in pSecTag2HygroA-CMV-mLec155 (herein referred to as pSec-mLec). For gene delivery in vivo, plasmid DNA $2 \mu \mathrm{g}$ per gram body weight in $100 \mu \mathrm{L}$ of saline per gram body weight, was injected over $5-8$ s via the tail vein.

\section{Murine model of in situ lung ischaemia-reperfusion injury}

Lung ischaemia-reperfusion injury was induced in mice as previously described [21]. Briefly, animals were anaesthetised with intraperitoneal pentobarbital $60 \mathrm{mg} \cdot \mathrm{kg}^{-1}$ (Nembutal; Sanofi, Brussels, Belgium) and kept at $37^{\circ} \mathrm{C}$. Animals were ventilated mechanically via an endotracheal tube $\left(120\right.$ strokes $\cdot \mathrm{min}^{-1} ; 320 \mu \mathrm{L}$ stroke volume) with $50 \%$ oxygen $\left(\mathrm{TM}^{\mathrm{LeD} / \mathrm{LeD}}\right.$ and $\mathrm{TM}^{\mathrm{wt} / \mathrm{wt}}$ mice) or room air (Swiss mice). The hilum of the left lung was occluded for $90 \mathrm{~min}$ via a left thoracotomy, followed by a reperfusion period of $4 \mathrm{~h}$. Mice were then sacrificed by ventilator switch-off.

\section{Bronchoalveolar lavage}

After sacrifice, bronchoalveolar lavage (BAL) was performed with the right lung clamped to obtain BAL fluid (BALF) from the left lung [21]. Four $0.5-\mathrm{mL}$ aliquots of sterile saline were gently instilled into the trachea. The returned fractions were centrifuged at $500 \times g$ for $10 \mathrm{~min}$ at $4{ }^{\circ} \mathrm{C}$. The supernatants of the first lavage were frozen and stored at $-80^{\circ} \mathrm{C}$ for subsequent analyses. Pellets of the four lavages were pooled in $250 \mu \mathrm{L}$ of saline for total and differential cell counts.

\section{Cell counts and protein assays}

Total cell counts in BALF were performed in triplicate using a Bürker chamber. Differential cell counts using cytospin preparations, on $\geqslant 300$ cells per sample, were determined as previously reported [21]. BALF IL-1 $\beta$ levels were measured in undiluted supernatants by ELISA (Biosource International, Nivelles, Belgium). Interferon (IFN)- $\gamma$, tumour necrosis factor (TNF)- $\alpha$, IL-2, granulocyte-monocyte colony-stimulating factor (GM-CSF), keratinocyte cytokine (KC), monocyte chemotactic protein (MCP)-1, and IL-6 were measured with Multiplex Cytometric Bead Array Flex kits (BD Biosciences, Erembodegem, Belgium). Total protein was quantified with the Bradford assay kit (Sigma, Bornem, Belgium). Plasma levels of thrombin-antithrombin (TAT) complexes and D-dimers were quantified by ELISA (Dade Behring, Brussels, Belgium).

\section{Lung histology and immunohistochemistry}

After BAL, the left lung was excised, fixed in $4 \%$ paraformaldehyde in PBS, and embedded in paraffin [21]. Transverse $10-\mu \mathrm{m}$ sections were cut and prepared for staining with haematoxylin and eosin (HE), or for immunostaining with antibodies against HMGB1 (Abcam, Cambridge, UK) or CD45 (Becton Dickinson, Erembodegem, Belgium). Quantification of cells per $400 \times$ high-power field (hpf) was performed manually on three nonoverlapping sections by an investigator blinded to the identity of the samples. Averages of a minimum of three measures for each lung were obtained, and the means of the results from six mice were obtained.

\section{Statistical analyses}

Results are presented as mean \pm SEM. Unpaired t-tests were used to identify differences between groups. When required, either a t-test with Welch correction, or the Mann-Whitney test was used. Correlation analyses were performed using a Pearson correlation test. A p-value $<0.05$ was considered significant.

\section{RESULTS}

\section{Lack of the LLD of TM increases BALF leukocyte and} cytokine levels after ischaemia-reperfusion injury

The role of the LLD of TM in lung ischaemia-reperfusion injury was examined by using a previously developed in situ murine model [21], and comparing the response of $\mathrm{TM}^{\mathrm{LeD} / \mathrm{LeD}}$ mice with their wild-type counterpart $\mathrm{TM}^{\mathrm{wt} / \mathrm{wt}}$ mice. $\mathrm{TM}^{\mathrm{LeD} / \mathrm{LeD}}$ mice lack the entire N-terminal LLD, including the C-type lectin-like module and the adjacent hydrophobic module. The 

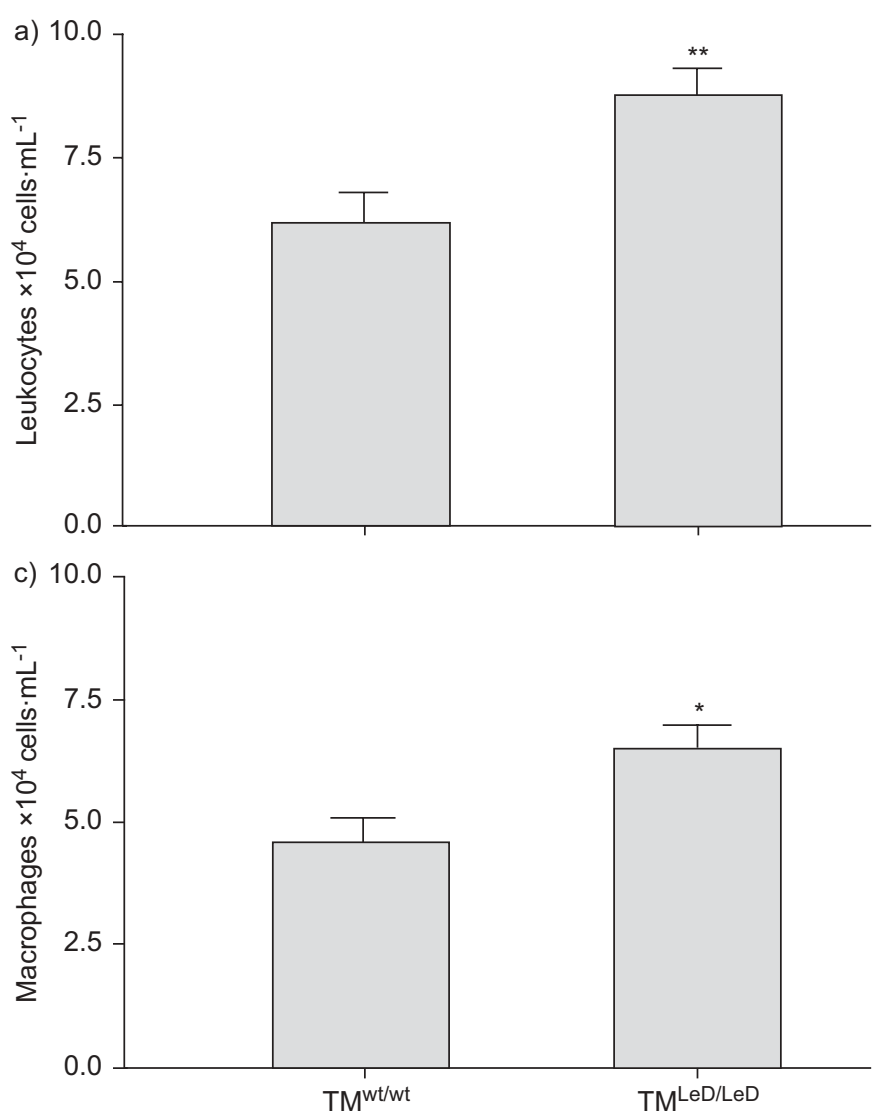
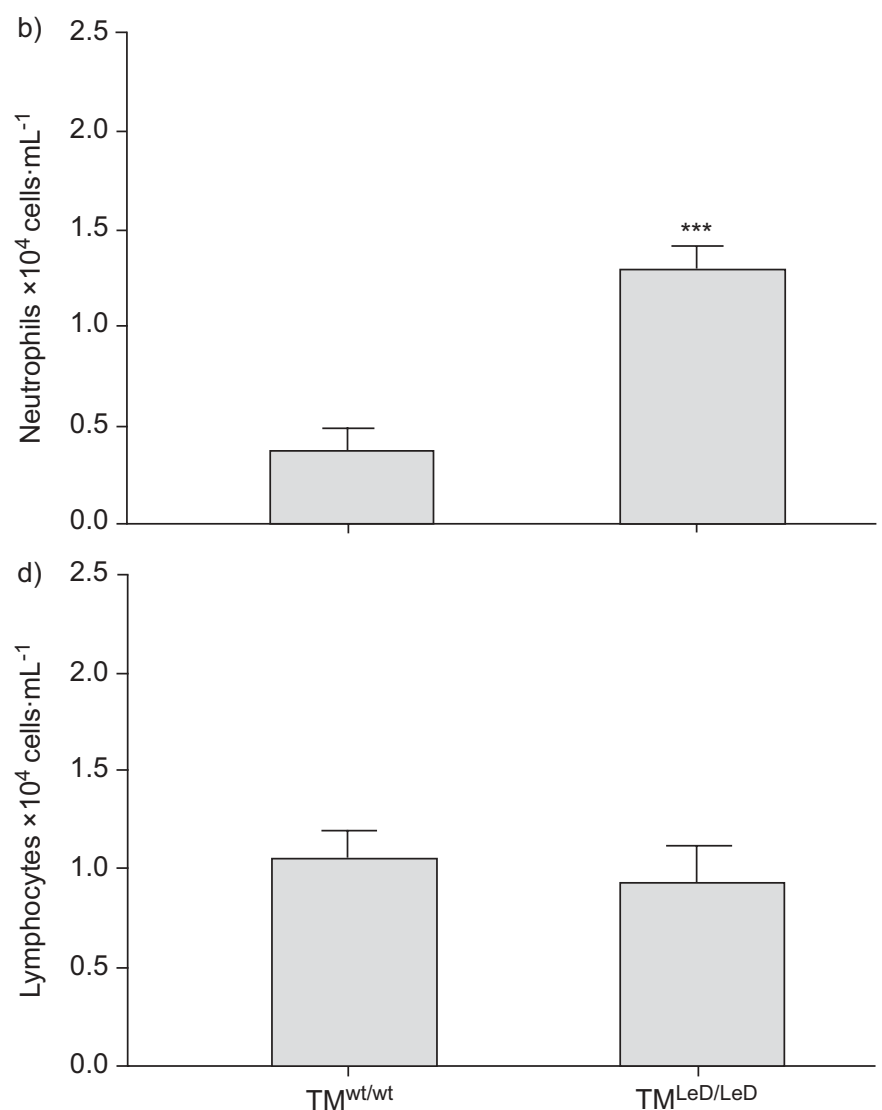

FIGURE 1. a-d) Lack of the lectin-like domain (LLD) of thrombomodulin (TM) augments bronchoalveolar lavage fluid (BALF) leukocytes after lung ischaemia-reperfusion injury. White cell counts in BALF from mice lacking the LLD of TM (TM ${ }^{\mathrm{LeD}} / T \mathrm{TM}^{\mathrm{LeD}}$ ) and their wild-type counteparts ( $\left(\mathrm{TM}^{\mathrm{w} t / \mathrm{wt}^{\prime}}\right.$ ) were quantified after lung ischaemia (90 min) and reperfusion $\left(4 \mathrm{~h}\right.$ ). $n=6$ mice per group. Lack of the LLD of TM resulted in significant increases in BALF neutrophils and monocytes. ${ }^{*}: p<0.05 ;{ }^{* *}: p<0.01 ; * * *: p<0.001$.

regimen of 90 min ischaemia followed by 4 h of reperfusion was previously demonstrated in the current authors' laboratory to induce BALF accumulation of leukocytes and cytokines in a temporal pattern comparable to that seen in other animal models [21, 22].

Under nonstress baseline conditions, analyses of BALF from $\mathrm{TM}^{\mathrm{LeD} / \mathrm{LeD}}$ or $\mathrm{TM}^{\mathrm{wt} / \mathrm{wt}}$ established that myeloperoxidase activities were not significantly different between $\mathrm{TM}^{\mathrm{wt} / \mathrm{wt}}$ and $\mathrm{TM}^{\mathrm{LeD} / \mathrm{LeD}}$ mice [21], consistent with a lack of spontaneous leukocyte infiltration into the alveolar space, and consistent with the absence of clinical disease in both.

In pilot studies, the present authors determined that it was not possible to perform the lung ischaemia-reperfusion injury protocol in the $\mathrm{TM}^{\mathrm{LeD} / \mathrm{LeD}}$ mice room air due to a high operative mortality rate. Thus, both the $\mathrm{TM}^{\mathrm{LeD} / \mathrm{LeD}}$ and the $\mathrm{TM}^{\mathrm{wt} / \mathrm{wt}}$ mice were ventilated with $50 \%$ oxygen during the entire ischaemia-reperfusion injury procedure, in which case no deaths were encountered.

Under these conditions, it was necessary to confirm that any changes that might occur in BALF accumulation of cytokines or leukocytes in response to ischaemia-reperfusion were not due to ventilation alone. Therefore, the mice were exposed to $5.5 \mathrm{~h}$ of ventilation with $50 \%$ oxygen ( $n=3$ per group). BALF was collected from the left lung and analysed. Both lungs were then harvested for histological analysis. Total leukocyte counts in the BALF of $\mathrm{TM}^{\mathrm{wt} / \mathrm{wt}}$ and $\mathrm{TM}^{\mathrm{LeD} / \mathrm{LeD}}$ mice were $2.9 \pm 0.1$ $\times 10^{4}$ cells $\cdot \mathrm{mL}^{-1}$ and $3.6 \pm 0.6 \times 10^{4}$ cells $\cdot \mathrm{mL}^{-1}$, respectively $(\mathrm{p}=0.363)$; total protein levels were $168 \pm 36 \mu \mathrm{g} \cdot \mathrm{mL}^{-1}$ and $192 \pm 7 \mu \mathrm{g} \cdot \mathrm{mL}^{-1}$, respectively ( $\mathrm{p}>0.5$ ); and cytokine levels (IL-1 $\beta$, GM-CSF, TNF- $\alpha$ ) were below the limits of detection of the assays in both groups. These results are no different from BALF studies without ventilation (data not shown). Thus, ventilation alone did not significantly alter the BALF results.

After lung ischaemia-reperfusion injury, the number of leukocytes in the BALF of the $\mathrm{TM}^{\mathrm{LeD} / \mathrm{LeD}}$ and the $\mathrm{TM}^{\mathrm{wt} / \mathrm{wt}}$ mice increased (fig. 1a). However, leukocyte counts in the $\mathrm{BALF}$ of $\mathrm{TM} \mathrm{LeD}^{\mathrm{LeD}}$ mice were significantly higher than in the $\mathrm{TM}^{\mathrm{wt} / \mathrm{wt}}$ mice $(\mathrm{n}=6 ; \mathrm{p}<0.01)$. Differential cell counts revealed that the higher BALF leukocyte counts from the reperfused lungs of the $\mathrm{TM}^{\mathrm{LeD} / \mathrm{LeD}}$ mice as compared with the $\mathrm{TM}^{\mathrm{wt} / \mathrm{wt}}$ mice were due to significant increases $(p<0.05)$ in both macrophages and neutrophils, without a notable difference in the number of lymphocytes (fig. 1). These cellular changes in the BALF of $\mathrm{TM}^{\mathrm{LeD} / \mathrm{LeD}}$ mice were associated with selective increases in cytokine levels (fig. 2). Thus, there were higher levels of IL-1 $\beta(p<0.001)$ and GM-CSF $(p<0.05)$ in the BALF of $\mathrm{TM}^{\mathrm{LeD} / \mathrm{LeD}}$ mice versus the $\mathrm{TM}^{\mathrm{wt} / \mathrm{wt}}$ mice. The number of macrophages correlated directly with IL-1 $\beta$ levels $(r=0.60$; $\mathrm{p}<0.05)$, while the number of neutrophils directly correlated with IL-1 $\beta(\mathrm{r}=0.79 ; \mathrm{p}<0.01)$ and GM-CSF $(\mathrm{r}=0.59 ; \mathrm{p}<0.05)$. Protein leakage was not notably affected by deletion of the 
LLD, since BALF total protein counts were similar $\left(569 \pm 70 \mu \mathrm{g} \cdot \mathrm{mL}^{-1}\right.$ versus $622 \pm 90 \mu \mathrm{g} \cdot \mathrm{mL}^{-1}$ in $\mathrm{TM}^{\mathrm{wt} / \mathrm{wt}}$ and $\mathrm{TM}^{\mathrm{LeD} / \mathrm{LeD}}$ mice, respectively). There were also no significant effects of deleting the LLD of TM on BALF levels of IL-6, KC, TNF- $\alpha$ or MCP-1 (fig. 2).

Microscopic examination of lung sections from the mice after ischaemia-reperfusion injury indicated notably more cellular infiltration into the lungs of $\mathrm{TM}^{\mathrm{LeD} / \mathrm{LeD}}$ mice as compared with their wild-type counterparts (fig. 3). Few cells were observed in the alveolar space, but this was attributed to bronchial lavage being performed prior to tissue preparation. CD45 staining confirmed the significantly increased lung infiltration with leukocytes $\left(12.3 \pm 1\right.$ cells $\cdot \mathrm{hpf}^{-2}$ and $24.2 \pm 3$ cells $\cdot \mathrm{hpf}^{-1}$ in $\mathrm{TM}^{\mathrm{wt} / \mathrm{wt}}$ and $\mathrm{TM}^{\mathrm{LeD} / \mathrm{LeD}}$ lungs, respectively; $\mathrm{n}=6$ per group, $p<0.005$; fig. 3). The histological changes could not be attributed either to the ventilation or to the lavage procedures. $\mathrm{TM}^{\mathrm{LeD} / \mathrm{LeD}}$ and $\mathrm{TM}^{\mathrm{wt} / \mathrm{wt}}$ mice were ventilated for $5.5 \mathrm{~h}$ as described, and, in addition to BALF from the left lung, both lungs were examined histologically. There were no discernible differences in the structure of the lungs under these otherwise baseline conditions, with only minimal evidence of neutrophil accumulation in the lung parenchyma of $\mathrm{TM}^{\mathrm{LeD} / \mathrm{LeD}}$ mice (fig. 3). Overall, the findings suggest that the LLD of TM confers protection against accumulation and extravasation of neutrophils and monocytes into the alveolar space in the setting of ischaemia-reperfusion injury.

HMGB1 is a pro-inflammatory cytokine, the action of which is, in part, regulated by the LLD of TM [20]. Recent studies suggest that HMGB1 may not only mediate late inflammatory events, but also may be involved in early events, i.e. in acute injury [23]. Moreover, HMGB1 has recently been shown to have pro-thrombotic effects by stimulating tissue factor and by interfering with PC activation [24]. The expression of HMGB1 in the lung sections of the $\mathrm{TM}^{\mathrm{wt} / \mathrm{wt}}$ and $\mathrm{TM}^{\mathrm{LeD} / \mathrm{LeD}}$ mice was examined in the present study before and after ischaemiareperfusion and, in that time frame, HMGB1 remained mostly localised to the nuclei, with minimal accumulation in the cytoplasm. HMGB1 was not detected in the BALF by ELISA (not shown). Plasma levels of the haemostatic markers, TAT and D-dimers were measured from $\mathrm{TM}^{\mathrm{wt} / \mathrm{wt}}$ and $\mathrm{TM}^{\mathrm{LeD} / \mathrm{LeD}}$ mice after lung ischaemia-reperfusion. Under baseline conditions or after ventilation only, there were no differences between the two mouse lines. Following ischaemia-reperfusion, D-dimers rose significantly over baseline (for $\mathrm{TM}^{\mathrm{wt} / \mathrm{wt}}$ mice; $15.5 \pm 7 \mathrm{ng} \cdot \mathrm{mL}^{-1}$ after reperfusion versus $1.6 \pm 0.4 \mathrm{ng} \cdot \mathrm{mL}^{-1}$ ventilation only; for $\mathrm{TM}^{\mathrm{LeD} / \mathrm{LeD}}$ mice; $20.9 \pm 7 \mathrm{ng} \cdot \mathrm{mL}^{-1}$ after reperfusion versus $2.6 \pm 0.9 \mathrm{ng} \cdot \mathrm{mL}^{-1}$ ventilation only), but the increases in the two mouse lines were not significantly
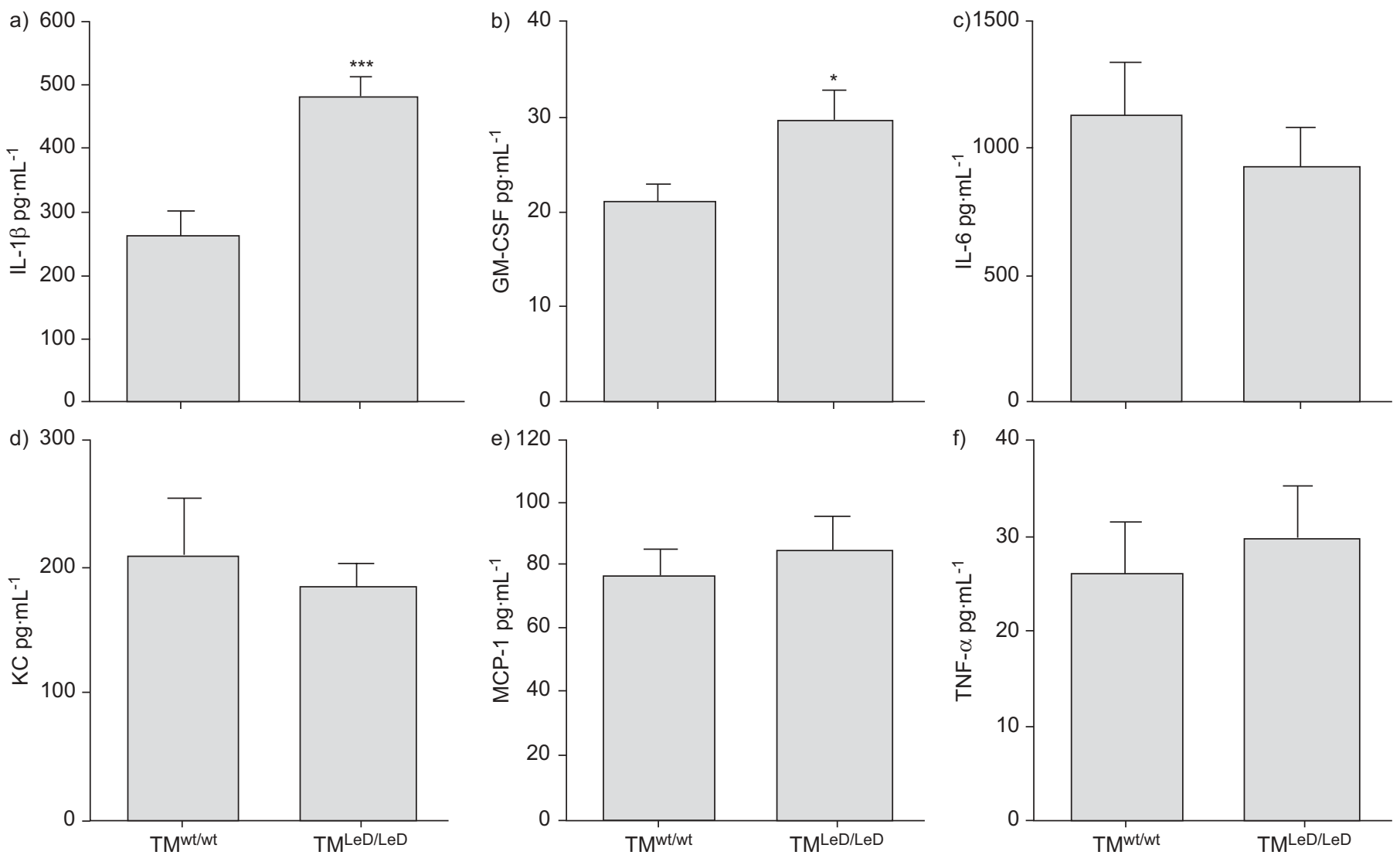

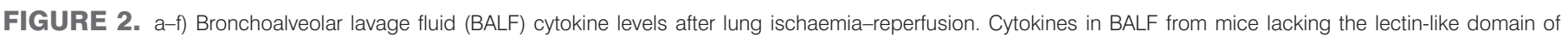

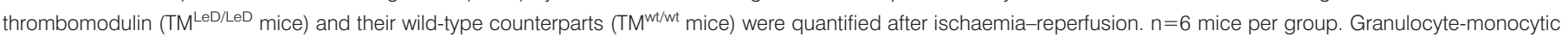

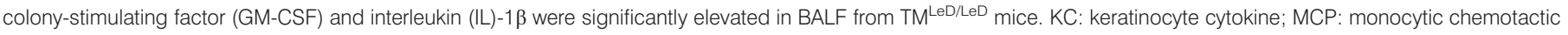
protein; TNF: tumour necrosis factor. ${ }^{*}: \mathrm{p}<0.05$; ${ }^{*}$ : $\mathrm{p}<0.01$; ${ }^{*} * *: \mathrm{p}<0.001$. 

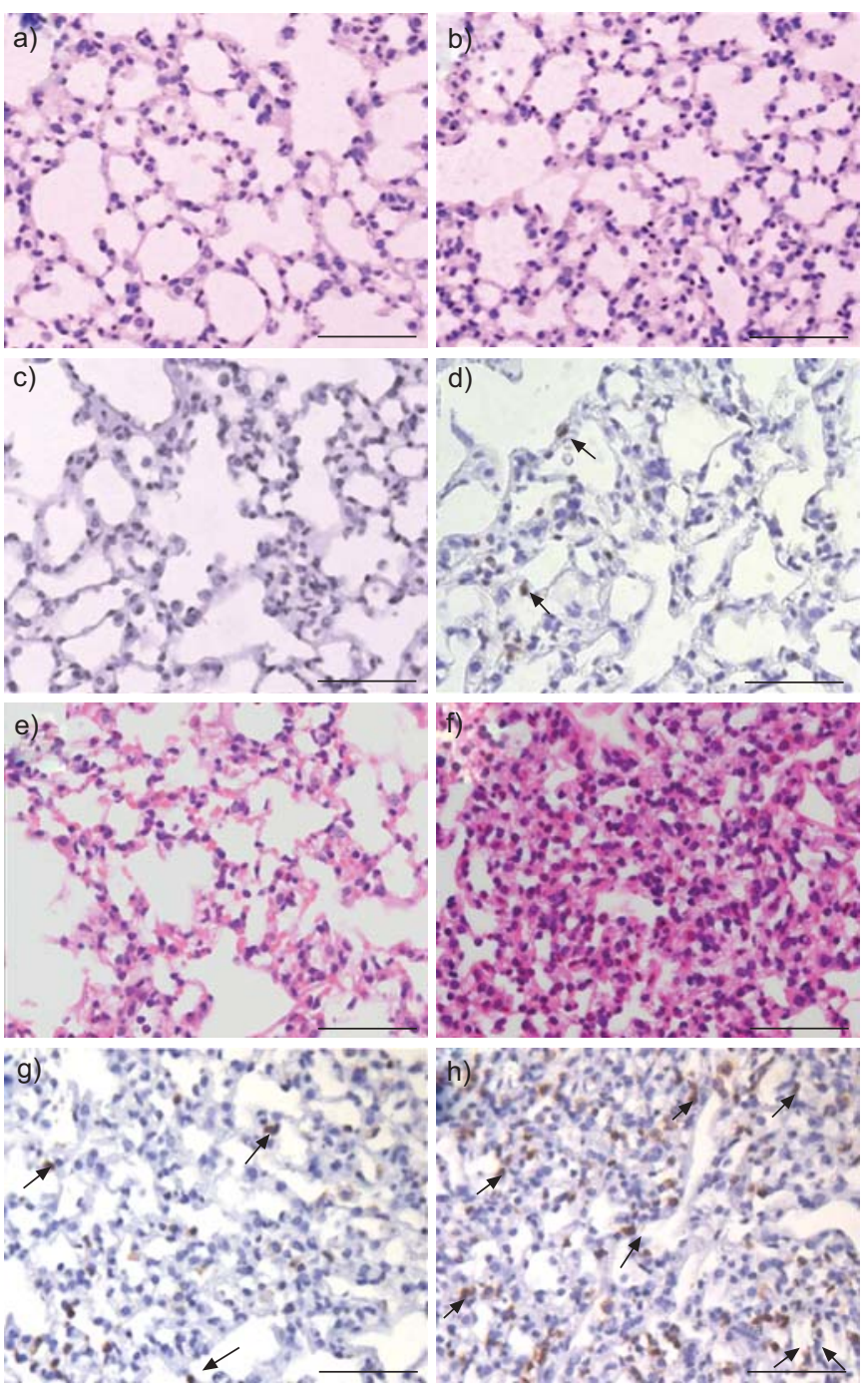

FIGURE 3. Histological sections of lungs from mice lacking the lectin-like domain of thrombomodulin ( $T M^{L e D / L e D} ; b, d, f$ and $h$ ) and their wild-type counterparts (TM ${ }^{\text {wt } / \mathrm{wt}} ; \mathrm{a}, \mathrm{c}, \mathrm{e}$ and $\mathrm{g}$ ) mice before and after ischaemia-reperfusion. Representative histological sections of lungs from mice before ( $a-d ; n=3$ per group) and after ischaemia-reperfusion (e-g; $\mathrm{n}=6$ per group) are shown, stained with haematoxylin and eosin $(a, c, e, g)$ or for $\operatorname{CD} 45(b, d, f, h)$ to identify leukocytes. Histological examination of sections from the left lungs of mice after $5.5 \mathrm{~h}$ of ventilation (no ischaemia) and collection of bronchoalveolar (BALF; a-d) was indistinguishable from the right lungs of corresponding mice (ventilation but no BALF collected), and also from baseline (no ventilation or BALF) (not shown). Only a few CD45-positive leukocytes (arrows in d) were detected in the parenchyma of lungs from $T M^{L e D / L e D}$ mice. e-h) After ischaemia-reperfusion, lung sections from $T_{M}^{L e D / L e D}$ mice $(g, h)$, as compared with those from $T M^{\text {wt/wt }}$ mice $(e, f)$, exhibited notably increased cellularity, and a significant increase in CD45-positive leukocytes $(\mathrm{g}, \mathrm{h})$. Scale bars $=50 \mu \mathrm{m}$.

different $(\mathrm{p}>0.5)$. In both the $\mathrm{TM}^{\mathrm{wt} / \mathrm{wt}}$ mice or the $\mathrm{TM} \mathrm{MeD}^{\mathrm{Le} / \mathrm{LeD}}$ mice, plasma accumulation of TAT complexes remained unchanged from baseline in response to ischaemia-reperfusion (data not shown; $\mathrm{p}>0.2$ ). Overall, when comparing the response to lung ischaemia-reperfusion injury in the $\mathrm{TM}^{\mathrm{wt} / \mathrm{wt}}$ and $\mathrm{TM}^{\mathrm{LeD} / \mathrm{LeD}}$ mice, differences in the haemostatic system activity or a differential role for HMGB1 could not be identified.

\section{Treatment with recombinant LLD of TM suppresses ischaemia-reperfusion injury}

Based on the heightened inflammatory response of the $\mathrm{TM}^{\mathrm{LeD} / \mathrm{LeD}}$ mice, the current authors predicted that administration of recombinant LLD of TM might protect against ischaemiareperfusion injury. The present authors have previously shown that hydrodynamic gene delivery of a cDNA vector (pSec-mLec) encoding the LLD of TM (the C-type lectin-like module) [19] protects against inflammatory arthritis in vivo, and that serum levels of the recombinant protein could be detected for up to $72 \mathrm{~h}$, peaking at $\sim 600 \mathrm{ng} \cdot \mathrm{mL}^{-1}$ at $6-24 \mathrm{~h}$. Therefore lung ischaemiareperfusion injury studies were performed on wild-type Swiss mice, pretreating them $24 \mathrm{~h}$ prior to clamping with pSec-mLec or with the vector-alone control ( $\mathrm{pSec} ; \mathrm{n}=6$ per group). Swiss mice were selected for these studies, because they tolerated room air (rather than requiring 50\% oxygen) during the procedure.

Treatment with pSec-mLec resulted in a significant decrease in the total number of BALF leukocytes following $90 \mathrm{~min}$ of ischaemia and $4 \mathrm{~h}$ of reperfusion $(\mathrm{p}<0.01$; fig. 4$)$, and this was due to a significant decrease in the number of macrophages $(p<0.01)$, lymphocytes $(p<0.05)$ and neutrophils $(p<0.001)$.

Gene delivery of recombinant LLD of TM caused a significant reduction in MCP-1 levels in the BALF as compared with the control pSec-treated mice $\left(139 \pm 13 \mathrm{pg} \cdot \mathrm{mL}^{-1}\right.$ with LLD versus $77 \pm 6 \mathrm{pg} \cdot \mathrm{mL}^{-1}$ with vector alone; $\mathrm{p}=0.0079 ; \mathrm{n}=6$ mice per group), while not affecting other measured cytokines. BALF protein levels decreased significantly with administration of the LLD (from $1165 \pm 140 \mu \mathrm{g} \cdot \mathrm{mL}^{-1}$ to $626 \pm 140 \mu \mathrm{g} \cdot \mathrm{mL}^{-1}$; $\mathrm{p}=0.0364$ ), suggesting protection against alveolar leakage. These responses, as compared with leukocyte and cytokine changes observed in the $\mathrm{TM}^{\mathrm{LeD} / \mathrm{LeD}}$ and $\mathrm{TM}^{\mathrm{wt} / \mathrm{wt}}$ mice, likely reflect strain differences, as has frequently been reported [25-28], or the effects of different local oxygen concentrations. Importantly, histological analyses of the lungs after ischaemia-reperfusion injury were also consistent with a beneficial effect of pretreatment with recombinant LLD (fig. 5). HE-stained lung sections from vector-alone treated mice revealed evidence of increased leukocyte infiltration that was diminished in the lungs from mice pretreated with pSec-mLec. CD45 staining of the lung sections (fig. 5) confirmed that administration of recombinant LLD of TM caused a significant reduction in the numbers of leukocytes in the lung parenchyma $\left(30.7 \pm 4\right.$ cells $\cdot \mathrm{hpf}^{-1}$ and $12.7 \pm 2$ cells $\cdot \mathrm{hpf}^{-1}$ with administration of pSec and pSec-mLec, respectively; $\mathrm{n}=6$ per group; $\mathrm{p}<0.005$ ).

\section{DISCUSSION}

In seeking innovative therapeutic approaches to interfere with lung injury associated with ischaemia-reperfusion, the current authors have drawn from advances in the understanding of the coagulation system, which have revealed the molecular basis underlying the links with the inflammatory system. The clinical relevance of this is best appreciated by the successful use of activated PC (APC), originally recognised for its anticoagulant properties, in decreasing sepsis-induced mortality in patients [29], and protecting against ischaemia-reperfusion injury in preclinical models [30]. The goal of the present study was to assess whether a structural domain of TM might also protect against ischaemia-reperfusion lung injury. 

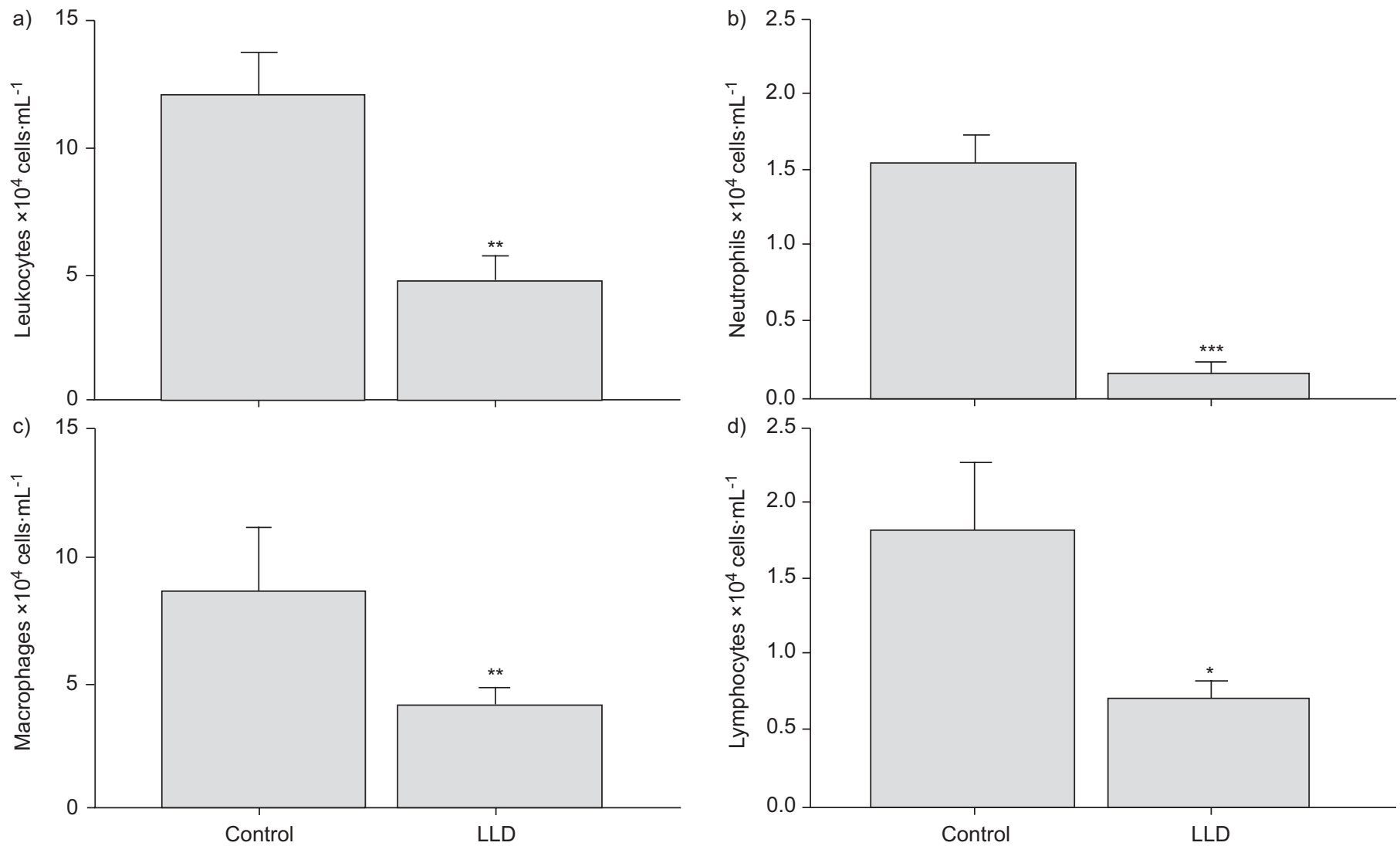

FIGURE 4. a-d) Bronchoalveolar lavage fluid (BALF) accumulation of leukocytes after treatment with recombinant lectin-like domain (LLD) of thrombomodulin (TM). White cell counts in BALF were quantified after lung ischaemia-reperfusion in mice that were pre-treated with recombinant LLD of TM via hydrodynamic gene delivery (LLD) or with the control vector-alone. $n=6$ mice per group. Treatment with recombinant LLD of TM significantly reduced all leukocytes. *: $p<0.05 ;{ }^{* *}: p<0.01 ; * \star *: p<0.001$.

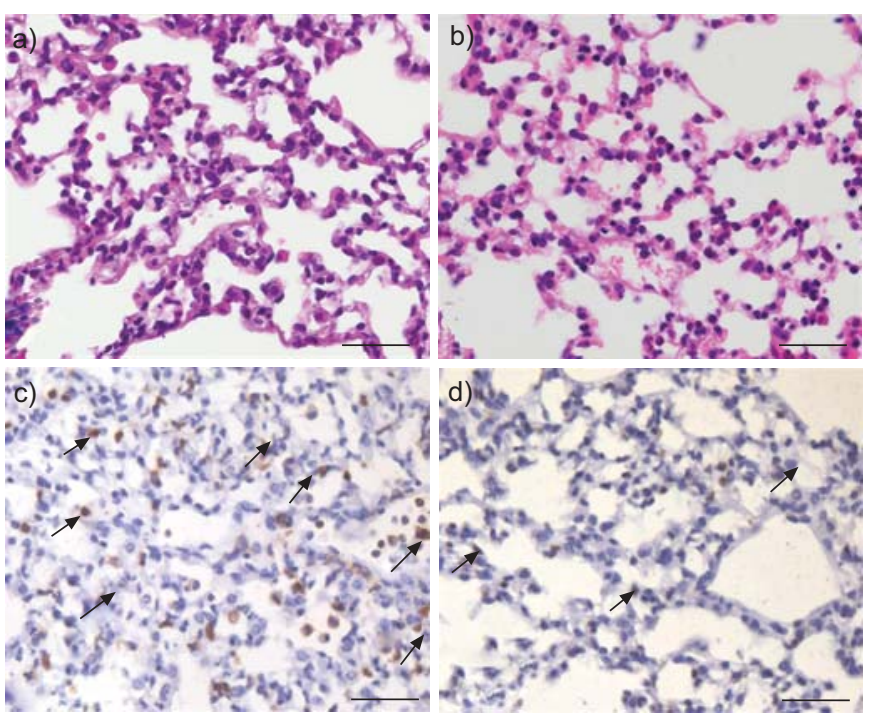

FIGURE 5. Histological changes in lungs in response to recombinant lectinlike domain (LLD) of thrombomodulin (TM). Representative histological sections of lungs from mice after ischaemia-reperfusion are shown ( $n=6$ per group), stained with haematoxylin and eosin ( $a$ and b) or for CD45 (c and d) to identify leukocytes. Mice pretreated with recombinant LLD of TM as compared with controls (a and c) exhibited a significant reduction in infiltration with leukocytes (arrows). Scale bars $=25 \mu \mathrm{m}$.
Full-length TM has multiple mechanisms by which it protects the vascular endothelium and underlying tissue, i.e. by modulating coagulation, fibrinolysis, cell proliferation, inflammation and innate immunity [17]. These are accomplished via direct and indirect interactions of its structural domains with several protein partners, including thrombin, PC, thrombinactivatable fibrinolysis inhibitor, the endothelial cell PC receptor (EPCR), platelet factor 4, HMGB1 and the complement system [31, 32]. Recombinant forms of TM that include the active anticoagulant EGF-like repeats have been used in vivo to interfere with sepsis, disseminated intravascular coagulation and lung injury, activities that are attributed to its cofactor activity for thrombin-mediated generation of APC $[33,34]$. As is the case for APC, the anticoagulant property of the EGF-like domain of TM, with its inherent risk of bleeding, raises concerns about its therapeutic use for ischaemia-reperfusion injury. Since the initiating events in ischaemia-reperfusion injury are primarily inflammatory in nature, it is reasonable to design therapeutic agents that target these steps, while avoiding haemorrhagic side-effects.

The LLD of TM does not directly affect the haemostatic system, but rather, it interferes with key pro-inflammatory intracellular signalling pathways, suppressing the expression of leukocyte adhesion molecules, tissue accumulation of neutrophils and monocytes [18], and the activation of complement pathways [19]. The wide array of protective effects of the LLD of TM in 
the inflammatory cascade prompted evaluation of its role in lung ischaemia-reperfusion injury. This was accomplished by using an established murine model of warm ischaemiareperfusion injury, in which changes in leukoctye trafficking and cytokine release, caused by genetic or pharmacological manipulation, could be quantified [21]. The present results showed that, as compared with matched wild-type controls, mice lacking the LLD of TM exhibited significantly higher BALF levels of macrophages and neutrophils, and these changes correlated with significantly elevated BALF concentrations of the cytokines IL-1 $\beta$ and GM-CSF. This enhanced inflammatory response in the $\mathrm{TM}^{\mathrm{LeD} / \mathrm{LeD}}$ mice cannot be attributed to alterations in thrombin-TM mediated activation of PC, since the EGF-like repeats of TM that are critical for PC activation are intact in the $\mathrm{TM}^{\mathrm{LeD} / \mathrm{LeD}}$ mice, and the antigenic levels of $\mathrm{TM}$ are the same as in $\mathrm{TM}^{\mathrm{wt} / \mathrm{wt}}$ mice. The current authors have previously confirmed that PC activation in vivo in the $\mathrm{TM} \mathrm{MeD}^{\mathrm{LeD}}$ mice is unaltered by loss of the LLD of TM [18]. Finally, the present study showed that the formation of TAT complexes and D-dimers in the blood was not altered after ischaemia-reperfusion by lack of the LLD of TM. Thus, the conclusion can be made that it is the lack of the LLD of TM, rather than diminished PC activation, that causes enhanced infiltration of leukocytes and augmented release of cytokines into the BALF of $\mathrm{TM}^{\mathrm{LeD} / \mathrm{LeD}}$ mice in this model of lung ischaemia-reperfusion injury.

These findings provided a strong rationale for testing the hypothesis that treatment with recombinant LLD might protect against lung ischaemia-reperfusion injury. Indeed, when the LLD of TM was administered via gene delivery prior to the ischaemia-reperfusion protocol, BALF accumulation of macrophages, lymphocytes and neutrophils, as well as total protein and MCP-1 levels, were significantly suppressed, as was neutrophil lung infiltration. Peripheral circulating blood counts were not measured, and thus it could not be determined whether the anti-inflammatory effects were localised or systemic. Nonetheless, the data provide evidence of the potential clinical utility of the LLD of TM in protecting against lung ischaemia-reperfusion injury.

The current lung ischaemia-reperfusion injury studies were restricted to a single reperfusion interval, as well as a single "dose". Thus, further study will be required to assess the short- and long-term effects of this intervention, as well as the physiological significance of the LLD-induced changes in cytokine release. IL-1 $\beta$, GM-CSF and MCP-1 are all inflammatory cytokines, each of which has been linked to the pathogenesis of tissue injury associated with ischaemia-reperfusion. MCP-1 is important for inflammation-associated monocyte recruitment and activation, as well as for neutrophil accumulation [35]. In a murine model of ischaemia-reperfusion injury similar to that used in the present study, ZHAO et al. [36] showed that MCP-1 expression is dependent on the presence of alveolar macrophages, and that BALF levels of MCP-1 and TNF- $\alpha$ correlate with the extent of lung injury. GM-CSF is best characterised by its ability to stimulate the mobilisation and proliferation of neutrophil and monocyte precursor cells. However, in the setting of ischaemia-reperfusion, it may also have pro-apoptotic effects, and thus contribute to tissue damage [37]. IL-1 $\beta$ plays a critical role in mediating the acute phase of the inflammatory response after ischaemia-reperfusion, and in a pig model of ischaemia-reperfusion injury, BALF levels of IL-1 $\beta$ correlate with graft function, suggesting that it may be a marker of graft viability [5]. Although the LLD of TM interferes with the activity of the proinflammatory HMGB1 [20], the present study did not detect differences in the subcellular pattern of expression of HMGB1 in the lung tissue sections of $\mathrm{TM}^{\mathrm{wt} / \mathrm{wt}}$ versus $\mathrm{TM} \mathrm{MeD}^{\mathrm{LeD}}$ mice or treated versus sham-treated mice. Indeed, even after the ischaemia-reperfusion lung injury, HMGB1 remained mainly localised to the nuclei, where it is not believed to exert a proinflammatory effect. Likewise, no differences in coagulation were detected between LLD-treated and sham-treated mice that might be differentially affected by HMGB1 release [24]. Until recently, HMGB1 was considered to be a late mediator of inflammation. Thus, it was not expected to play a role in the present model of acute ischaemia-reperfusion injury. However, HMGB1 is now also recognised to mediate acute inflammation, including, for example, the response to severe haemorrhagic lung injury [23]. The inability of the current authors to demonstrate a contribution of HMGB1 may be explained by several factors, including, for example, the type and duration of the stress, its relative severity and the strain of mice. Nonetheless, the findings do not exclude the possibility that the LLD of TM might still confer protection via HMGB1 after ischaemia-reperfusion injury at time periods beyond those evaluated. Overall, the current authors are confident from these studies that the LLD of TM does modulate cytokine release, and that this is reflected by therapy-induced attenuation in the number of leukocytes accumulating in the lung and entering the alveoli after reperfusion. More extensive analyses will provide insights into when the LLD of TM acts, and on which cell populations it is most active.

After systemic gene delivery of the LLD and $4 \mathrm{~h}$ of lung ischaemia-reperfusion injury, LLD could not be detected in the BALF. Likewise, increased deposition of the LLD in the lung parenchyma could not be confirmed [19], either by Western immunoblotting of lung lysates or by immunohistochemical staining of tissue sections (not shown). However, even in the setting of inflammation, where TM levels are suppressed [38], the endogenous expression of TM in the lung vasculature is relatively high, and recombinant LLD of TM could not be distinguished from endogenous sources. Thus, further study is required to identify the precise mechanisms by which the LLD of TM protects the lungs against ischaemia-reperfusion injury. In addition to interfering with leukocyte adhesion to endothelial cells and suppressing complement activation, the LLD does have direct anti-apoptotic effects on cultured endothelial cells [18], and one or more of these mechanisms may account for its protective role. Increased $\mathrm{C} 1 \mathrm{q}$ or $\mathrm{C} 3$ deposition could not be detected in the lungs of the TM ${ }^{\mathrm{LeD} / \mathrm{LeD}}$ mice (not shown). In addition, the effects of the LLD on pulmonary epithelium have not been examined, although alveolar type-II cells may express $\mathrm{TM}$ and release proteolytic fragments of TM [39]. It is notable that APC, which has anti-inflammatory and anti-apoptotic effects on several cells, including lung epithelial cells, shares several intracellular signalling pathways with the LLD of TM, including suppression of NF- $\mathrm{\kappa B}$ translocation and MAP kinase activation [40]. APC, however, acts primarily via activation of protease-activated receptor-1 and EPCR [41], while it is not yet fully understood how the LLD of TM regulates intracellular 
signalling pathways. Nonetheless, it is likely that APC and the LLD of TM act cooperatively, and delineating how this occurs at a molecular level will provide important therapeutic insights.

In view of the overwhelming success of lung transplantation in saving lives of patients with end-stage lung disease, there is an urgent need to develop multiple approaches that may be used singly or in combination to prevent ischaemia-reperfusion injury, thereby substantially decreasing morbidity and mortality. The present authors have, for the first time, demonstrated that the lectin-like domain of thrombomodulin, a molecular fragment with potent anti-inflammatory properties but lacking anticoagulant effects, may be a useful adjunct in preventing ischaemia-reperfusion injury of the lung, and future studies will determine its utility in models of lung transplantation.

\section{ACKNOWLEDGEMENTS}

This study was presented in part at the 27th Annual Meeting and Scientific Sessions of the International Society for Heart and Lung Transplantation, San Francisco, CA, USA, April 2528,2007

\section{REFERENCES}

1 De Perrot M, Liu M, Waddell TK, Keshavjee S. Ischemiareperfusion-induced lung inury. Am J Respir Crit Care Med 2003; 167: 490-511.

2 King RC, Binns OA, Rodriguez F, et al. Reperfusion injury significantly impacts clinical outcome after pulmonary transplantation. Ann Thorac Surg 2000; 69: 1681-1685.

3 De Perrot M, Sekine Y, Fischer S, et al. Interleukin-8 release during early reperfusion predicts graft function in human lung transplantation. Am J Respir Crit Care Med 2002; 165: 211-215.

4 Serrick C, Adoumie R, Giaid A, Shennib H. The early release of interleukin-2, tumour necrosis factor- $\alpha$ and interferon- $\gamma$ after ischemia reperfusion injury in the lung allograft. Transplantation 1994; 58: 1158-1162.

5 Rega FR, Vanaudenaerde BM, Wuyts WA, et al. IL-1 $\beta$ in bronchial lavage fluid is a non-invasive marker that predicts the viability of the pulmonary graft from the non-heart-beating donor. J Heart Lung Transplant 2005; 24: 20-28.

6 Ovechkin AV, Lominadze D, Sedoris KC, Robinson TW, Tyagi SC, Roberts AM. Lung ischemia-reperfusion injury: implications of oxidative stress and platelet-arteriolar wall interactions. Arch Physiol Biochem 2007; 113: 1-12.

7 Naka Y, Marsh HC, Scesney SM, Oz MC, Pinsky DJ. Complement activation as a cause for primary graft failure in an isogeneic rat model of hypothermic lung preservation and transplantation. Transplantation 1997; 64: 1248-1255.

8 Sekido N, Mukaida N, Harada A, Nakanishi I, Watanabe Y, Matsushima K. Prevention of lung reperfusion injury in rabbits by a monoclonal antibody against interleukin-8. Nature 1993; 365: 654-657.

9 Inci I, Zhai W, Arni S, Hillinger S, Vogt P, Weder W. Nacetylcysteine attenuates lung ischemia-reperfusion injury after lung transplantation. Ann Thorac Surg 2007; 84: 240-246.

10 Gazoni LM, Tribble CG, Zhao MQ, et al. Pulmonary macrophage inhibition and inhaled nitric oxide attenuate lung ischemia-reperfusion injury. Ann Thorac Surg 2007; 84 247-253.

11 Naidu BV, Farivar AS, Woolley SM, Grainger D, Verrier ED, Mulligan MS. Novel broad-spectrum chemokine inhibitor protects against lung ischemia-reperfusion injury. J Heart Lung Transplant 2004; 23: 128-134.

12 Stammberger U, Hamacher J, Pache JC, Schmid RA. $\mathrm{sCR}_{\mathrm{sLe}} \mathrm{X}^{\mathrm{r}}$ reduces lung allograft ischemia-reperfusion injury but does not ameliorate acute rejection. Eur J Cardiothorac Surg 2002; 22: 368-372.

13 Otani Y, Takeyoshi I, Yoshinari D, Matsumoto K, Morishita Y. Effects of the COX-2 inhibitor FK3311 on ischemiareperfusion injury in the rat lung. J Invest Surg 2007; 20: 175-180.

14 Ishiyama T, Dharmarajan S, Hayama M, Moriya $H$, Grapperhaus K, Patterson GA. Inhibition of nuclear factor $\kappa \mathrm{B}$ by $\mathrm{I} \kappa \mathrm{B}$ superrepressor gene transfer ameliorates ischemia-reperfusion injury after experimental lung transplantation. J Thorac Cardiovasc Surg 2005; 130: 194-201.

15 Okazaki M, Kreisel F, Richardson SB, et al. Sphingosine 1phosphate inhibits ischemia reperfusion injury following experimental lung transplantation. Am J Transplant 2007; 7: 751-758.

16 Rivo J, Zeira E, Galun E, Einav S, Linden J, Matot I. Attenuation of reperfusion lung injury and apoptosis by A2A adenosine receptor activation is associated with modulation of Bcl-2 and Bax expression and activation of extracellular signal-regulated kinases. Shock 2007; 27: 266-273.

17 Van de Wouwer M, Collen D, Conway EM. Thrombomodulin-protein C-EPCR system. Integrated to regulate coagulation and inflammation. Arterioscler Thromb Vasc Biol 2004; 24: 1374-1383.

18 Conway EM, Van de Wouwer M, Pollefeyt S, et al. The lectin-like domain of thrombomodulin confers protection from neutrophil-mediated tissue damage by suppressing adhesion molecule expression via nuclear factor $\kappa \mathrm{B}$ and mitogen-activated protein kinase pathways. J Exp Med 2002; 196: 565-577.

19 Van de Wouwer M, Plaisance S, DeVries A, et al. The lectin-like domain of thrombomodulin interferes with complement activation and protects against arthritis. J Thromb Haemost 2006; 4: 1813-1824.

20 Abeyama K, Stern DM, Ito Y, et al. The N-terminal domain of thrombomodulin sequesters high-mobility group-B1 protein, a novel antiinflammatory mechanism. J Clin Invest 2005; 115: 1267-1274.

21 Geudens N, Vanaudenaerde BM, Neyrinck AP, et al. Impact of warm ischemia on different leukocytes in bronchoalveolar lavage from mouse lung: possible new targets to condition the pulmonary graft from the nonheart-beating donor. J Heart Lung Transplant 2006; 25: 839-846.

22 Eppinger MJ, Deeb GM, Bolling SF, Ward PA. Mediators of ischemia-reperfusion injury of rat lung. Am J Pathol 1997; 150: 1773-1784.

23 Fan J, Li Y, Levy RM, Fan JJ, et al. Hemorrhagic shock induces $\mathrm{NAD}(\mathrm{P}) \mathrm{H}$ oxidase activation in neutrophils: role of HMGB1-TLR4 signaling. I Immunol 2007; 178: 6573-6580. 
24 Ito T, Kawahara K, Nakamura T, et al. High-mobility group box 1 protein promotes development of microvascular thrombosis in rats. J Thromb Haemost 2007; 5: 109-116.

25 Dodd-o JM, Hristopoulos ML, Welsh-Servinsky LE, Tankersley CG, Pearse DB. Strain-specific differences in sensitivity to ischemia-reperfusion lung injury in mice. $J$ Appl Physiol 2006; 100: 1590-1595.

26 Chen X, Oppenheim JJ, Howard OM. BALB/c mice have more CD4+CD25+ $\mathrm{T}$ regulatory cells and show greater susceptibility to suppression of their CD4+CD25-responder T cells than C57BL/6 mice. J Leukocyte Biol 2005; 78: 114-121.

27 Weiler H, Lindner V, Kerlin B, et al. Characterization of a mouse model for thrombomodulin deficiency. Arterioscler Thromb Vasc Biol 2001; 21: 1531-1537.

28 Whitehead GS, Walker JK, Berman KG, Foster WM, Schwartz DA. Allergen-induced airway disease is mouse strain dependent. Am J Physiol Lung Cell Mol Physiol 2003; 285: L32-L42.

29 Bernard GR. Drotrecogin alfa (activated) (recombinant human activated protein C) for the treatment of severe sepsis. Crit Care Med 2003: 31: Suppl. 1 S85-S93.

30 Levi M, Choi G, Schoots I, Schultz M, Van Der Poll T. Beyond sepsis: activated protein $\mathrm{C}$ and ischemia-reperfusion injury. Crit Care Med 2004; 32: S309-S312.

31 Esmon CT. Crosstalk between inflammation and thrombosis. Maturitas 2004; 47: 305-314.

32 Esmon CT. Structure and functions of the endothelial cell protein C receptor. Crit Care Med 2004; 32: Suppl. 5, S298-S301.

33 Saito H, Maruyama I, Shimazaki S, et al. Efficacy and safety of recombinant human soluble thrombomodulin (ART123) in disseminated intravascular coagulation: results of a phase III, randomized, double-blind clinical trial. J Thromb Haemost 2007; 5: 31-41.

34 Uchiba M, Okajima K, Murakami K, Johno M, Okabe H, Takatsuki K. Recombinant thrombomodulin prevents endotoxin-induced lung injury in rats by inhibiting leukocyte activation. Am J Physiol 1996; 271: L470-L475.

35 Maus U, Huwe J, Maus R, Seeger W, Lohmeyer J. Alveolar JE/MCP-1 and endotoxin synergize to provoke lung cytokine upregulation, sequential neutrophil and monocyte influx, and vascular leakage in mice. Am J Respir Crit Care Med 2001; 164: 406-411.

36 Zhao M, Fernandez LG, Doctor A, et al. Alveolar macrophage activation is a key initiation signal for acute lung ischemia-reperfusion injury. Am J Physiol Lung Cell Mol Physiol 2006; 291: L1018-L1026.

37 Bedirli A, Soyuer I, Muhtaroglu S, Guler I. Role of granulocyte-macrophage colony-stimulating factor on apoptosis induced by ischemia-reperfusion in the intestinal epithelium. Eur Surg Res 2003; 35: 357-362.

38 Cone JB, Ferrer TJ, Wallace BH, Wang J, Hauer-Jensen M. Alterations in endothelial thrombomodulin expression in zymosan-induced lung injury. J Trauma 2003; 54: 731-736.

39 Ware LB, Fang X, Matthay MA. Protein C and thrombomodulin in human acute lung injury. Am J Physiol Lung Cell Mol Physiol 2003; 285: L514-L521.

40 Suzuki K, Gabazza EC, Hayashi T, Kamada H, Adachi Y, Taguchi O. Protective role of activated protein C in lung and airway remodeling. Crit Care Med 2004; 325: Suppl. 5, S262-S265.

41 Riewald M, Petrovan RJ, Donner A, Ruf W. Activated protein $C$ signals through the thrombin receptor PAR1 in endothelial cells. J Endotoxin Res 2003; 9: 317-321. 